\title{
1. Introduction: rethinking the politics of intellectual property
}

\author{
Sebastian Haunss and Kenneth C. Shadlen
}

Information and knowledge constitute the building blocks of culture, industry, and science. We use this simple observation as the point of departure in this book, where we examine the politics of information and knowledge. How conflicts over the ownership, control and use of these building blocks are resolved has consequences that are of fundamental importance in our everyday lives and, on a more macro scale, in patterns of growth, prosperity and development in the global economy. The rules on how information and knowledge are owned and controlled affect how individuals and collectivities access and use cultural products, along with media and entertainment goods. Because rules on information and knowledge influence the terms by which actors can access critical information - and knowledge-intensive goods such as books, medicines, and seeds, they affect national strategies to reduce poverty, achieve food security, and protect public health. And by affecting patterns of technological development and diffusion and the distribution of the gains from technological change, rules on the ownership and use of knowledge affect national and international trajectories of economic development.

With the importance of these issues increasingly recognized, the past decade has witnessed a veritable explosion of literature on intellectual property (IP). Analysts have explained the introduction of new and stringent IP rules in the international trading system, focusing on the establishment of the World Trade Organization (WTO)'s Agreement on Trade-Related Aspects of Intellectual Property Rights (TRIPS), subsequent conflicts in the WTO over the relationship between TRIPS and public health and biodiversity, and the introduction of IP in a range of regional and bilateral initiatives (Beigbeder 2004; Bessen and Raskind 1991; Correa 2000; Drahos and Braithwaite 2003; Drahos 2005; Hein et al. 2007; Klug 2008; Maskus 2000; May 2007; Pugatch 2006; Sell 2002, 2003; Shadlen 2005, 2007a; Shadlen et al. 2005). This immense body of research has both significantly advanced the academic attention to the topic of IP and greatly enhanced our understanding of the topic. 
Seen from the vantage point of political analysis, however, and at the risk of oversimplification, the current literature suffers from two weaknesses. First, the field is overly generalized, with too much attention paid to the conflicts over international (global and regional) rules and legal provisions at the expense of analysis of what is happening within countries. Certainly, international rules, whether TRIPS or the IP provisions of regional and bilateral trade agreements (RBTAs), impose constraints on national policy and establish the parameters of what sorts of policies are permissible. Yet within these parameters the questions of how actors respond to external constraints and how countries go about implementing their externally-derived obligations warrant significantly more attention than they typically receive. The prevailing focus on the international arena and on external sources of IP policy change means that we still have little appreciation and understanding of these latter sets of questions.

Scholars and students who want to learn about the global politics of IP, such as the origins of the TRIPS Agreement and the integration of IP into RBTAs, have countless texts to choose from (for example, Drahos 1995; Ryan 1998; May and Sell 2005; Sell 2003; Maskus 2000; Correa 2000; Matthews 2002; Shadlen 2005; Watal 2001). Yet scholars and students looking for analyses of IP policy-making lack such resources. In addition, most studies focus on national and international IP laws. But while laws are the solidified results of social struggles and political conflicts, understanding the law itself tells us little about the social processes that lay behind laws and even less about the social dynamics that will eventually challenge and often change them. Laws establish opportunities for action, and strictly legal perspectives in most cases say little about different actors' motivations and capacities to exploit these opportunities and how the motivations and capacities change over time (Shadlen 2007b). It is time, therefore, to reorient analysis of the politics of IP to the processes by which conflicts over the ownership, use, and control of information are manifest and resolved in regional, national and sub-national settings.

A second - and arguably more problematic - weakness of the field is that it is insufficiently theorized in a political sense: not enough attention is given to how the politics of IP may be informed by distinct dynamics and logics. Analysts of the politics of IP typically treat the issue area like any other area of political analysis: we identify actors' conflicting interests and study how these conflicts are resolved. Of course, the processes of interest formation, alliance building, and political mobilization are key aspects of politics. The analytic challenge is to see how these processes are (or are not) different when the conflicts in question are over ownership, control, and use of knowledge and information. Indeed, for most economic and legal scholarship on IP, the fundamental characteristics of knowledge and 
information serve as the starting point. That is, because knowledge and information - the underlying entities that IP converts into property - are non-rivalrous and inexhaustible, or because they are typically the result of multiple producers' efforts over considerable periods of time, or because the nature of innovation is such that it is difficult to distinguish the inputs from the outputs in knowledge generation, or because they have extremely uncertain boundaries, scholars emphasize that the economics and law of IP differ from the economics and law of tangible "normal" property (Arrow 1962; Scotchmer 1991, 2004; Helpman 1993; David 1993; Merges and Nelson 1990; Boyle 1997; Hettinger 1989; Lemley and Shapiro 2005; Thambisetty 2007; Bessen and Meurer 2008). We believe that there are good reasons to assume that the specific characteristics of knowledge and information lead to a different sort of politics as well. At least there are good reasons to probe deeper and to examine in greater depth how and under which circumstances IP politics differs from other policy fields.

Building upon the substantial body of research on the politics of IP, this book begins to address these shortcomings. The contributions discuss how rules governing the ownership, control, and use of knowledge and information are made and implemented. The authors focus on distinct areas of contestation, identify the relevant actors and the processes by which collective actors come to be, their modes of interest and preference formation and strategies of political mobilization, and analyze the mechanisms of resolving disputes between actors with conflicting interests. Importantly, the authors attempt to show where and how these processes - the basic ingredients of politics - appear different in the area of IP; and they do so with empirical studies of conflicts about the governance of information and knowledge from the developed and developing world. In this introductory chapter we present some initial and exploratory thoughts about what a more theoretically-grounded approach to the politics of IP might look like, and we provide an overview of the subsequent chapters.

\section{KNOWLEDGE, INFORMATION, AND POLITICS}

A distinguishing feature of the politics of knowledge and information is that the separation between the spheres of production and consumption is usually weak and sometimes non-existent. In processes of knowledge production, inputs are transformed - but usually not in the way tangible inputs are transformed in processes of industrial production. The scientific knowledge that is used in research projects is not fundamentally different from the knowledge that is produced in this process. Nor are there categorical differences between the knowledge authors and musicians draw 
upon and the books and music that are the product of their labor. These observations are not meant to deny that new knowledge is generated, nor to negate actors' inventive and creative contributions. Yet in contrast to industrial production processes, where for example ore is transformed into iron which is then transformed into a street sign (to consider one basic segment of a single production chain), there appears to be little if any corresponding categories of raw material (such as ore), intermediate input (such as iron), and final product (such as street sign) in the process of generating scientific or cultural knowledge. The conversion of ore into iron and iron into our street sign fundamentally transforms the inputs, and additional industrial processes would then be required to restore them to their previous states. That is not the case in knowledge production: producers of knowledge are also users of the same types of knowledge. The raw materials that contribute to new music and literature are the same ideas and forms of expression that already-existing music and literature consists of; likewise, generating new computer software entails increasingly complex machinations of zeros and ones, but at the end of the day we are still left with zeros and ones. Here the notion of prosumers (Toffler 1980 ) is not an empty phrase but a social reality that fundamentally structures the policy field. This is true for the biochemical knowledge used to make medicines too.

The relationship between consumption and production described above appears quite different if we take into account the actual industrial processes that are used to produce tangible goods based on knowledge and information. Printing and binding forms of expression, producing CD-ROMS and DVDs, and manufacturing medicines based on biochemical knowledge, for example, all yield outputs that are fundamentally different from their inputs; and this form of industrial production does require a distinction between users and producers, as the former rarely have the capital and equipment to undertake industrial production on a commercial scale. Yet these tangible products are the delivery containers, not themselves the protected IP, and the need for capital and skills to produce the delivery containers is conditional on the prior existence of the underlying knowledge and information. To be sure, in some areas the delivery vehicles themselves have changed, so music and software can be distributed without tangible CDs and DVDs. Yet even these changes entail processes of physical and industrial transformation, such as the creation of the necessary broadband infrastructure, and these industrial transformations are separate from - and subsequent to - the transformations of the knowledge and information that yield the underlying information content. In the case of knowledge and information themselves, the lines between inputs (consumption) and outputs (production) are remarkably blurry. 
It is not just the blurry borders between inputs and outputs that distinguish knowledge and information, but also the additive relationship between inputs and outputs. We know that one person's use of knowledge and information does not affect the amount available for others to use; that is, the consumption of knowledge and information is non-rivalrous. But it is more than that: the use or consumption of knowledge and information can actually increase - and not reduce - the stock of knowledge and information. Not only can knowledge and information be consumed without affecting its availability for others, but its consumption, in turn, generates more knowledge and information. Pupils and students in schools and universities do not "use up" the knowledge and information that is delivered to them. On the contrary, teaching creates more (of the same and sometimes even new) knowledge without diminishing the stock of existing knowledge. Thus, knowledge and information are not like the lighthouse that can be used by every ship off the coast; they are more like a lighthouse that, once built in one place, can provide orientation for ships off each and every coast.

These observations have profound implications for IP politics. On the one hand, given the breadth of user communities, we may expect to see broader and more fluid constituencies for IP rules that facilitate the use of knowledge and information. We may therefore expect to see unusual coalitions which will nevertheless be confronted - because of their fluidity, size, and dispersion - with familiar collective action problems. We may on the other hand expect the constituencies for restrictive IP to be fairly narrow, and therefore better able to advance their cause, an expectation that appears well supported by the many studies of industry-based mobilization during the TRIPS negotiations (for example, Drahos 1995; Ryan 1998; Matthews 2002; Sell 2003). But since we witness in some issue areas surprising outcomes of intellectual property conflicts, a closer look at the collective action dynamics is necessary (Haunss and Kohlmorgen forthcoming).

An additional and related implication of the intangible character of knowledge and information is that political conflicts over IP tend to be prone to dynamics of increasing returns. The beneficiaries of strong IP policies accumulate resources that allow them to press for further strengthening, and institutions created to implement and enforce IP tend to push in this direction as well, while those actors who are disadvantaged by strengthened IP systems often experience diminished capacity to mobilize for reforms that would loosen IP rules and facilitate use. Strong IP systems are therefore likely to generate a comparatively small group of winners who profit significantly and, in turn, have a strong interest in maintaining and further strengthening the system. In addition to what is 
well known about industrial actors in biotech and content-based sectors, other especially interesting actors in this respect are patent professionals and university administrators/scientists. The former generally profit from stronger IP regimes that guarantee increased incomes, while the latter may perceive stronger IP regimes as presenting opportunities to make scientific research more profitable or may perceive them as constraining university budgets and limiting the freedom of academic research.

These dynamics are addressed by a number of authors in this book, whose chapters show in particular that opposition to restrictive IP policies is often strongest when these policies generate immediate negative material effects. Rising costs of medication as a result of stronger IP laws and the ensuing mobilization and resistance are one example of this phenomenon. Yet episodes of mobilization tend to be facilitated by particular conjunctures of actors and events that are far from automatic. Building and sustaining alliances to reform IP laws are extraordinarily complex and difficult processes. Indeed, many of the chapters in this volume focus on patterns of collective action in IP politics, and in particular how users and owners of knowledge often exhibit very different - and asymmetrical - patterns of political mobilization. They especially pay attention to unexpected alliances and patterns of mobilization around IP, and in doing so reveal the limitations of general mechanisms for understanding the increasingly contentious politics of IP. In Europe, for example, software programmers were able to mobilize mass protest against a project to reform patent law while consumers were unable to do so with regard to copyright enforcement.

The immaterial character of knowledge and information also makes policies that aim to restrict the use of knowledge by establishing IP and enforcing IPRs immensely challenging and thus dependent on significant regulatory efforts and expense. This unavoidable feature of IP, of course, means that the gaps between laws and reality are often immense. While analysts may be focusing on the former, actors' interests and political strategies are shaped by the latter, leading, again, to unexpected patterns of behavior. The high visibility and efforts required to enforce IP also give importance to framing processes. To the extent that restricting access to knowledge is framed as a necessary precondition to innovation and improving economic welfare, the costs and efforts of doing so may appear justified. Yet if exclusion from knowledge is framed as an obstacle to innovation, cultural flourishing, and economic development, then the costs of doing so may be more easily targeted by opponents. It is precisely for this reason that so many of the chapters in this volume focus on the process of framing and the role that epistemic communities play in altering the boundaries of IP politics. 


\section{CHAPTER OVERVIEWS}

The book begins with four chapters that explore a range of conflicts over the ownership, use, and control of information and knowledge in the developing world. Kenneth Shadlen examines two sets of conflicts over patents that have emerged in most developing countries in the aftermath of the TRIPS agreement. Most governments have faced pressures to modify aspects of their IP systems regarding pharmaceutical patents, and at the same time most governments have also faced pressures to modify aspects of their patent systems more broadly related to science, technology, and innovation. In both realms we witness cross-national variation in terms of outcomes, and Shadlen's chapter points to both the cross-national differences and, moreover, over-arching cross-national similarities in the two sets of conflicts. The findings in his chapter, based largely on three Latin American cases, have broad implications for processes of interest formation and political mobilization. In particular, Shadlen emphasizes fundamental asymmetries, how beneficiaries of patent systems tend to mobilize more than those who are disadvantaged, and among the disadvantaged how resistance tends to be stronger in areas related to health and drugs than in areas related more broadly to technology, innovation, and economic development.

Gaëlle Krikorian offers one of the first in-depth political analyses of a country exploiting the flexibilities available under the TRIPS agreement. Krikorian shows how, despite an adverse global setting, Thailand issued compulsory licenses on a set of patented medications. Her chapter demonstrates the importance of understanding how political opportunity structures affect the ability of different actors to participate in and influence outcomes in conflicts over IP. In particular, Krikorian focuses on the role of the Thai Ministry of Health and health-oriented civil society organizations (CSOs), and how the government-CSO alliance was able to overcome the intense opposition of the transnational pharmaceutical sector and trade officials from the European Union and the United States of America. Krikorian's analysis has a counter-intuitive finding in that a military coup served to help CSOs advance their demands on the state to issue compulsory licenses. By focusing on the politics of CLs, the chapter also points to the limitations of work that emphasizes legal dimensions per se, for the real question in the Thai case was not the legality of the CLs but the country's ability to exploit its legal prerogatives. Though writing of a "successful" case, Krikorian's conclusion is decidedly less optimistic: if so many factors and conditions must come together in just the right way to make issuing CLs feasible, it would appear that the "effective political flexibilities" of the TRIPS agreement are significantly less than the agreement's formal legal flexibilities. 
Ronald Herring and Milind Kandlikar's chapter on the politics of $\mathrm{Bt}$ cotton in India illustrates how the capacities and interests of state and non-state actors involved in conflicts over control and use of technology can be significantly more complex than suggested by conventional wisdom. The analysis points to the fundamental limitations of states' abilities to control biotechnology, and the unexpected distribution of the gains from technological innovation that may obtain in such a setting. In general, one output of government efforts to control biotechnology are biosafety regulations that slow authorization for legal use of transgenics. As Herring and Kandlikar explain, biosafety regulations can be functionally equivalent to IP regulations, in that both restrict the range of actors that can participate in technology markets. In the case of $\mathrm{Bt}$ cotton in India, however, biosafety restrictions have been routinely bypassed by a wide range of rural actors (entrepreneurs and farmers) that created a vibrant market for "stealth seeds". The rise of these markets and the subsequent widespread use of "stealth seeds" represents a clear case of the use of technology outpacing the regulatory terrain. Moreover, the proliferation of stealth seeds not only presents farmers with unexpected opportunities to appropriate the benefits of technological innovation but also creates new alliances of actors that demand revised biosafety regulations.

Sabil Francis's chapter on the control and use of traditional knowledge illustrates the limitations of conventional political and social categories, as well as unexpected patterns of political mobilization. As Francis shows, western concepts of ownership are unable to capture the complexities involved in analysis of traditional knowledge. Using the arogyapacha case, he shows how even well-meaning benefit sharing agreements reach their limits because the concept of intellectual property assumes a clear attribution of ownership and relies on national institutions to administer the rights. Traditional knowledge often cannot be easily attributed nor are its holders necessarily concentrated in only one national territory. Yet assigning rights to traditional communities requires that someone "speak for the tribe". Thus, Francis's chapter shows how the adoption of IP by indigenous communities necessarily creates the actors needed for the IP system to function properly, and thereby invariably changes the dynamics within local communities.

The next two chapters focus on the discursive level of recent conflicts about intellectual property rights in Europe. The authors analyze how the meaning of intellectual property is established and re-interpreted in framing processes, and how collective actors sharing a common interpretation of the issues at stake and sharing a collective action frame guiding their activities are created. 
Sebastian Haunss and Lars Kohlmorgen analyze two contemporary IP conflicts in Europe, one regarding the patenting of software and the other regarding the enforcement of copyrights. The authors utilize a framing approach to explain why seemingly "weak" actors from small and medium-sized enterprises and civil society were able to prevail over a broad coalition of extremely resource-rich business interests in the case of software, while civil society actors were unable to provide significant opposition against the music industry in the case of copyyright enforcement. Haunss and Kohlmorgen's focus on discourse and framing points to the processes by which collective actors in IP conflicts are created and to the strategies that actors use to politicize ostensibly technical issues. These framing processes, the authors show, can have enduring effects on IP politics by reconfiguring constellations of actors who participate and the balance of power and influence among relevant actors. Indeed, similar processes of framing and politicization are evident in many of the IP conflicts analyzed in this book.

Ingrid Schneider analyzes the framing processes surrounding the introduction of biopatents in Europe. She shows how the involvement of non-governmental organizations and the European Parliament altered prevailing perceptions of biopatents from technical to political issues. This politicization changed the public perception of responsibility for this issue. Framing biopatents as an ethics issue brought in the parliament as an political actor, sidelining patent lawyers and technicians in the patent offices that had traditionally been perceived as being responsible for patent issues. Schneider shows how initially a frame that presented biopatents as an ethical problem managed to gain currency in opposition to industry's alternative frame that presented patents on biological material as a strictly economic issue. But in a subsequent - and unexpected - process the ethical frame was adopted by biopatent supporters to advance their interests in a second round of the conflict.

In contrast to other chapters' emphasis on agency and framing, Lars Bretthauer's chapter on the politics of copyright in the Germany movie industry provides an explicitly structural perspective. Bretthauer explains how the reconfiguration of laws regulating this sector, in particular the strengthening of copyrights for digital media, is the consequence of strategic imperatives established by a neoliberal approach to seeking national competitiveness. Against the hegemony of neoliberalism, actors projecting and proposing alternative approaches to digital copyright were unable to articulate alternatives successfully. Yet Bretthauer's analysis also points to the cracks in the hegemonic model: the widespread practice of on- and offline sharing of digital movies, the discussion on a so-called "culture flat rate", and the provisions strengthening authors" 
rights against production and distribution rights show how IP issues are embedded in ongoing social conflicts about the shape of the knowledge society.

The book closes with two contributions that take a more detailed look at patenting practices and the patent system. Hazel Moir presents an empirical analysis of the users of the patent system in the US and Australia. Drawing on data on patent applications, grants, and renewals, she shows that patent ownership in both countries is highly concentrated among a small group of companies owning hundreds or even thousands of patents whereas the large majority of patentees own only a handful of patents. Her finding that the overwhelming majority of benefits of the patent systems accrue to a tiny minority of the actors involved challenges the notion that patents serve "industry" as a whole - not to mention the effects on society more broadly. Indeed, Moir makes a valiant effort to evaluate the effects of the patent system on "patent losers", an exceedingly difficult empirical exercise that is rarely done.

In the concluding chapter, Sivaramjani Thambisetty draws our attention to the tendency of patent systems to be subject to processes of increasing returns. In doing so, Thambisetty weds the literature from law (and a substantial amount of case law) with recent literature from political science that points to how actors that accumulate resources under given policy arrangements can use their gains to secure additionnal benefits, thus creating dynamics marked by self-reinforcement and increasing returns. Her insight is that patent systems have a set of attributes that make them very much subject to such processes, and she provides analysis of the doctrinal and institutional factors that underpin the propensity toward ever-expanding and ever-increasing IP rights. Thambisetty focuses on a particular set of mechanisms that perpetuate processes of increasing returns, such as the overlapping authority of courts, patent offices and other specialized IP agencies, and the idiosyncrasies of legal doctrines in the US and the UK. She also explains a critical asymmetry in patent law, that on the one hand there is a tendency toward issuing patents and allowing litigation to correct for errors in patent examination and granting, but on the other hand there are inherent biases against litigating (such as costs and inability to appropriate the benefits of successfully invalidating a patent). Together, these processes of selfreinforcement and increasing returns have been driving forces behind the continuous expansion of the breadth and scope of the patent system in recent decades. Her analysis contradicts the conventional wisdom that the expansion of the patent system would be rational from an economic perspective and points to important and so far overlooked internal dynamics of the legal system. 


\section{REFERENCES}

Arrow, Kenneth J. (1962), 'Economic Welfare and the Allocation of Resources for Invention', in Richard Nelson (ed.), The Rate and Direction of Inventive Activity, Princeton: Princeton University Press, pp. 609-26.

Beigbeder, Yves (2004), International Public Health: Patients' Rights vs the Protection of Patents, Aldershot: Ashgate.

Bessen, James, and Michael J. Meurer (2008), Patent Failure: How Judges, Bureaucrats, and Lawyers Put Innovators at Risk, Princeton: Princeton University Press.

Bessen, Stanley M., and Leo J. Raskind (1991), 'An Introduction to the Law and Economics of Intellectual Property', Journal of Economic Perspectives 5(1): 3-27.

Boyle, James (1997), 'A Politics of Intellectual Property: Environmentalism for the Net?', Duke Law Journal 47(1): 87-116.

Correa, Carlos Maria (2000), Intellectual Property Rights, the WTO and Developing Countries. The TRIPS Agreement and Policy Options, London: Zed Books.

David, Paul A. (1993), 'Intellectual Property Institutions and the Panda's Thumb: Patents, Copyrights, and Trade Secrets in Economic Theory and History', in Mitchel B. Wallerstein, Mary E. Mogee, and Robin A. Schoen (eds), Global Dimensions of Intellectual Property Rights in Science and Technology, National Academies Press, pp. 19-61.

Drahos, Peter (1995), 'Information Feudalism in the Information Society', The Information Society 11(3): 209-22.

Drahos, Peter (2005), 'Global Property Rights in Information: The Story of TRIPS at the GATT', Prometheus 13(1): 6-19.

Drahos, Peter, and John Braithwaite (2003), Information Feudalism. Who Owns the Knowledge Economy?, New York: New Press.

Haunss, Sebastian, and Lars Kohlmorgen (forthcoming), 'Conflicts About Intellectual Property Claims: The Role and Function of Collective Action Networks', Journal of European Public Policy.

Hein, Wolfgang, Sonja Bartsch, and Lars Kohlmorgen (eds) (2007), Global Health Governance and the Fight Against HIVIAIDS, Basingstoke: Palgrave Macmillan.

Helpman, Elhanan (1993), 'Innovation, Imitation, and Intellectual Property Rights', Econometrica 61(6): 1247-80.

Hettinger, Edwin C. (1989), 'Justifying Intellectual Property', Philosophy and Public Affairs 18(1): 31-52.

Klug, Heinz (2008), 'Law, Politics, and Access to Essential Medicines in Developing Countries', Politics \& Society 36(2): 207-45.

Lemley, Mark A., and Carl Shapiro (2005), 'Probabilistic Patents', Journal of Economic Perspectives 19(2): 75-98.

Maskus, Keith E. (2000), Intellectual Property Rights in the Global Economy, Washington, DC: Institute for International Economics.

Matthews, Duncan (2002), Globalising Intellectual Property Rights: The TRIPS Agreement, New York: Routledge.

May, Christopher (2007), The World Intellectual Property Organization: Resurgence and the Devleopment Agenda, 1st edn, London and New York: Routledge. 
May, Christopher, and Susan K. Sell (2005), Intellectual Property Rights: A Critical History, Boulder, CO: Lynne Rienner.

Merges, Robert P., and Richard R. Nelson (1990), 'On the Complex Economics of Patent Scope', Columbia Law Review 90(4): 839-916.

Pugatch, Meir (2006), 'Political Economy of Intellectual Property Policy-Making: Theory and Practice - An Observation from a Realistic (and Slightly Cynical) Perspective', paper presented at the AHRC Copyright Research Network Workshop on Network Theme 6 (Copyright, Corporate Power and Human Rights), London.

Ryan, Michael P. (1998), Knowledge Diplomacy. Global Competition and the Politics of Intellectual Property, Washington, DC: Brookings Institution Press.

Scotchmer, Suzanne (1991), 'Standing on the Shoulders of Giants: Cumulative Research and the Patent Law', The Journal of Economic Perspectives 5(1): $29-41$.

Scotchmer, Suzanne (2004), Innovation and Incentives, Boston, MA: MIT Press.

Sell, Susan K. (2002), 'Intellectual Property Rights', in David Held and Anthony G. McGrew (eds), Governing Globalization. Power, Authority and Global Governance, Cambridge: Polity, pp. 171-88.

Sell, Susan K. (2003), Private Power, Public Law. The Globalization of Intellectual Property Rights, Cambridge studies in international relations, 88, Cambridge: Cambridge University Press.

Shadlen, Kenneth C. (2005), 'Exchanging Development for Market Access? Deep Integration and Industrial Policy under Multilateral and Regional-Bilateral Trade Agreements', Review of International Political Economy 12(5): 750-75.

Shadlen, Kenneth C. (2007a), 'Intellectual Property, Trade, and Development: Can Foes Be Friends?', Global Governance 13(2): 171-7.

Shadlen, Kenneth C. (2007b), 'The Political Economy of AIDS Treatment: Intellectual Property and the Transformation of Generic Supply', International Studies Quarterly 51(3): 559-81.

Shadlen, Kenneth C., Andrew Schrank, and Marcus J. Kurtz (2005), 'The Political Economy of Intellectual Property Protection: The Case of Software', International Studies Quarterly 49(1): 45-71.

Thambisetty, Sivaramjani (2007), 'Patents as Credence Goods', Oxford Journal of Legal Studies 27(4): 707-40.

Toffler, Alvin (1980), The Third Wave, New York: Bantam.

Watal, Jayashree (2001), Intellectual Property Rights in the World Trade Organization: The Way Forward for Developing Countries, New Dehli: Oxford University Press (India). 